\title{
Transnasal endoscopy in a patient with cicatricial pemphigoid
}

\author{
M. Rodríguez-Téllez , Q. Arroyo-Martínez ${ }^{2}$, C. Lizarralde ${ }^{3}$, F. J. Pellicer ${ }^{1}$ and J. M. Herrerías² \\ ${ }^{1}$ Endoscopy Unit, ${ }^{2}$ Digestive Diseases Department, and ${ }^{3}$ Pathology Department. University Hospital Virgen Macarena. \\ Sevilla, Spain
}

\section{CASE REPORT}

A 32-year-old male referring asthmatic bronchitis, corticoid-associated cicatricial pemphigoid, osteoporosis secondary to the use of corticoids and steroid cataracts, is sent to our Unit due to persistent oropharyngeal dysphagia. Conventional endoscopy is programmed in two different days and, subsequent to the failure of the procedure, oral approach is carried out in a vain attempt with a $5.9 \mathrm{~mm}$ endoscope. Transnasal route is then considered (Fig. 1), resulting successful as multiple ulcerous lesions and fibrous portions of the hypopharynx can be observed, which are hardly overcome. No other le-

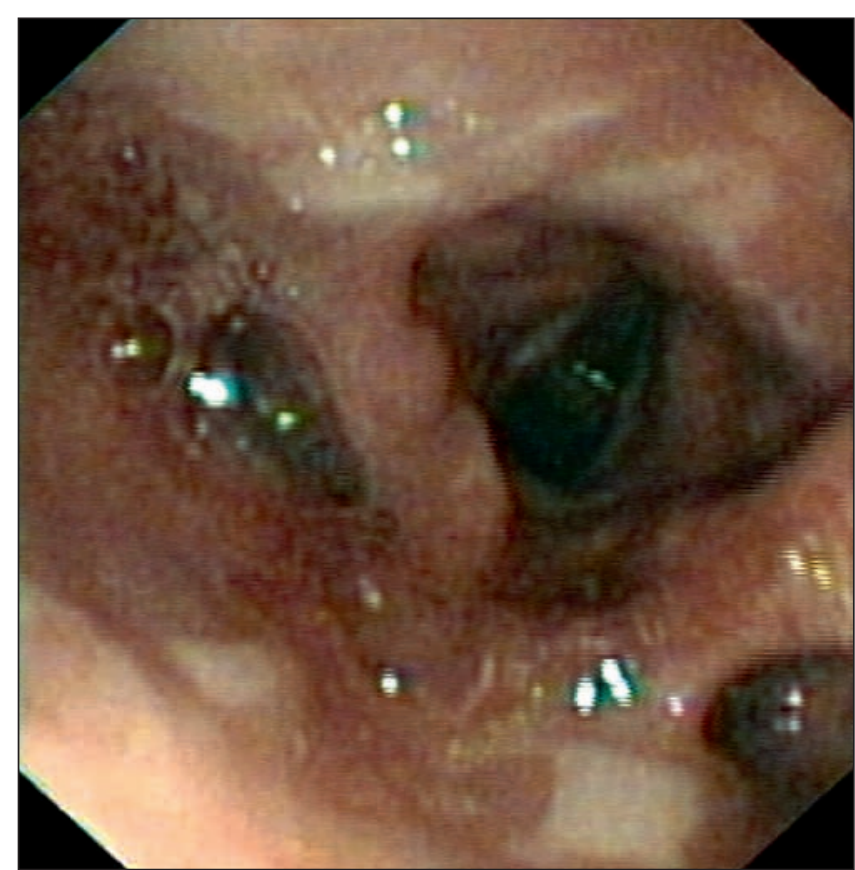

Fig. 1. Transnasal endoscopy: multiple ulcerous lesions are observed in the hypopharynx, and fibrous portions on the anterior side of the epiglottis as others that make difficult the entrance through Killian's area. sions were observed along the esophagic or gastric mucosa as well as the second duodenal portion. A posterior pharynx biopsy revealed the presence of subepidermal split, vesiculobullous mucosa with subepitelial hemorrhage and granulation tissue in the submucous (Fig. 2).

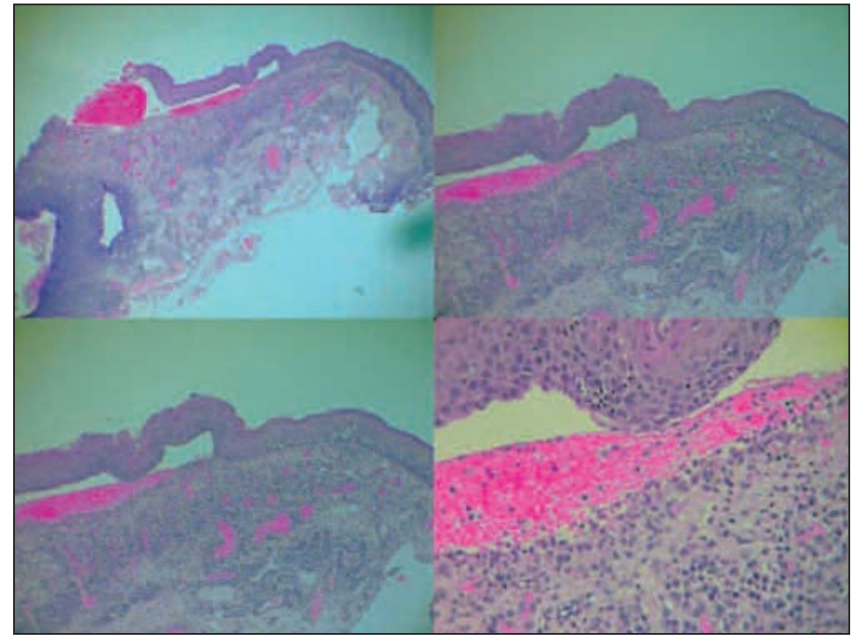

Fig. 2. Subepidermal split with vesiculobullous mucosa. Subepitelial hemorrhage and granulation tissue in the submucous with neutrophilic infiltrate were present. Hematoxilin and eosin.

\section{DISCUSSION}

Cicatricial pemphigoid is a benign, autoimmune, chronic inflammatory disease, characterised by a slow and progressive evolution with spontaneous exacerbation outbreaks and remission periods. It is mainly observed in the oral cavity, affecting the superficial mucosa. When dysphagia is observed, it is due to a secondary involvement of the hypopharynx because of ulcerations which may also produce fibrous portions in the upper tract of the esophagus, leading to persistent dysphagia (1). Although present in only 5\% of the cases, esophagus-gastric affection should also be considered. It may 
also affect the conjunctiva, larynx, genitals and skin (2). Narrow endoscopes $(<6 \mathrm{~mm})$ were developed in the $90 \mathrm{~s}$, in order to decrease discomfort and costs derived from anesthesic procedures associated with the conventional method. Transnasal endoscopy has been used not only with a diagnostic purpose, but also therapeutic, describing several procedures such as PEG and feeding nasogastric tube implantation (3). It represents a safe technique for the upper digestive tract evaluation, with minimal adverse effects, therefore we consider it useful and safe in these patients $(4,5)$.

\section{REFERENCES}

1. Altenburg A, Krahl D, Zouboulis CC. Non-infectious ulcerating oral mucous membrane diseases. JDDG J. German Soc Dermatol 2009; 7: 242-57.

2. Naylor MF, MacCarty NL, Rogers RS. Barium studies in esophageal cicatricial pemphigoid. Abdom Imaging 1995; 20 : 97-100.

3. Vitale MA, Villotti G, D'Alba L, De Cesare MA, Frontespezi S, Iacopini G. Unsedated transnasal percutaneous endoscopic gastrostomy placement in selected patients. Endoscopy 2005; 37: 48-51.

4. Dumortier J, Napoleon B, Hedelius F, Pellissier PE, Leprince E, Pujol B, et al. Unsedated transnasal EGD in daily practice: results with 1100 consecutive patients. Gastrointest Endosc 2003; 57: 198-204

5. Postma GN, Cohen JT, Belafsky PC, Halum SL, Gupta SK, Koufman JA. Transnasal esophagoscopy: revisited (over 700 consecutive cases). Laryngoscope $2005 ; 115: 321-3$. 